\title{
Superior Paraolivary Nucleus of the Rat Is a GABAergic Nucleus
}

\author{
Randy J. Kulesza, JR., And Albert S. Berrebi \\ Departments of Otolaryngology and Anatomy, Neuroscience Graduate Program and Sensory Neuroscience Research Center, \\ West Virginia University School of Medicine, Morgantown, WV 26506-9200, USA
}

Received: 30 June 2000; Accepted: 8 September 2000; Online publication: 23 November 2000

\section{ABSTRACT}

The presence of the inhibitory neurotransmitters glycine and GABA (gamma-amino butyric acid) and GAD (glutamic acid decarboxylase), the synthesizing enzyme for GABA, was examined by immunocytochemistry in the superior paraolivary nucleus (SPON) of the rat. Only rarely were SPON neurons observed to be glycine-immunoreactive, but the majority were GABA-immunoreactive. Using unbiased stereological counting methods, we estimated that this nucleus contains approximately 2500 neurons. Moreover, $90 \%$ of SPON neurons were immunolabeled by antisera directed against either the 65 - or $67-\mathrm{kD}$ isoform of GAD, or a third antiserum that recognizes both GAD isoforms. Morphometric analysis of GAD-immunolabeled neurons indicated that SPON neurons possess cell bodies and dendritic arbors that are elongated rostrocaudally and relatively flattened parasagittally. Abundant glycine-, GABA-, and GAD-immunoreactive punctate profiles-presumed to represent, for the most part, presynaptic axon terminals-were observed in apposition to SPON neurons. We conclude that the rat SPON contains a homogeneous population of multipolar GABAergic neurons that receive abundant GABAergic and glycinergic innervation. The vast majority of glycinergic inputs to SPON are presumed to originate in the ipsilateral medial nucleus of the trapezoid body, but the source(s) of its GABAergic innervation remains to be determined.

Correspondence to: Dr. Albert S. Berrebi, Ph.D. • Department of Otolaryngology • West Virginia University School of Medicine • P.O. Box 9200, Health Sciences Center • Morgantown, WV 26506. Telephone: (304) 293-2357; fax: (304) 293-2902; email: aberrebi@wvu.edu
Keywords: superior olive, dorsomedial periolivary nucleus, glycine, glutamic acid decarboxylase

\section{INTRODUCTION}

Inhibition plays a crucial role in the vertebrate nervous system, and glycine and gamma-aminobutyric acid (GABA) are the major inhibitory neurotransmitters in the CNS (Nicholls 1994). Although glycine is a common amino acid present in all proteins and cells, GABA is synthesized from the amino acid glutamate by the enzyme glutamic acid decarboxylase (GAD) (Roberts and Frankel 1950; Nicholls 1994). Because GABA is a small labile molecule that can be difficult to localize with immunocytochemistry, GAD is widely considered a reliable marker for GABAergic neurons (Wu et al. 1973; Oertel et al. 1981). Two isoforms of GAD, named according to their molecular weights, have been isolated (Bayon et al. 1977; Spink et al. 1983; Denner and Wu 1985; Legay et al. 1987; Kaufman et al. 1991). Although both GAD isoforms are present in most GABAergic neurons, GAD 65 and GAD 67 (65 and $67 \mathrm{kDa}$, respectively) are transcribed from separate genes and have different affinities for the cofactor pyridoxal 5'-phosphate (Erlander et al. 1991; Martin et al. 1991; Kaufman et al. 1991). Recent immunocytochemical studies suggest that the two isoforms may have different intracellular distributions, with GAD 67 being widely distributed in somata, dendrites, and axon terminals, while GAD 65 is located predominantly in axon terminals (Esclapez et al. 1994). GAD 67 , which is present as the active holoenzyme, is presumably responsible for utilizing glutamate, through the GABA shunt, for metabolic needs or supplying basal levels of GABA for neurotransmission (Denner 
and Wu 1985; Erlander and Tobin 1991). In contrast, GAD 65 is active only in the presence of cofactor and synthesizes GABA in terminals when there is increased demand (Martin and Rimwall 1993).

The neurotransmitters GABA and glycine are found in abundance in central auditory nuclei, and inhibitory neurotransmission plays a fundamentally important role in the function of the mammalian auditory system (Helfert and Aschoff 1997). Inhibition has been shown to sharpen tuning curves and modulate discharge properties of auditory neurons, and it is crucial to the ability to localize high-frequency sounds (Finlayson and Caspary 1989; Yang et al. 1992; Caspary et al. 1994; Park and Pollak 1993; Klug et al. 1995; Le Beau et al. 1996; Koch and Grothe 1998). GABAergic and glycinergic neurons are especially prominent in the superior olivary complex (SOC) (Helfert et al. 1989; Spirou and Berrebi 1997; Saint Marie and Baker 1990; Ostapoff et al. 1990, 1997). This auditory brainstem center contains three principal nuclei with identified roles in sound localization, the medial nucleus of the trapezoid body (MNTB), the medial superior olive (MSO) and the lateral superior olive (LSO), and several accessory or periolivary cell groups whose roles in audition are poorly understood (Schwartz 1992; Helfert and Aschoff 1997).

The superior paraolivary nucleus (SPON) is a conspicuous periolivary nucleus in the SOC of rodents and guinea pigs. Situated medial to the LSO and dorsolateral to the MNTB, this nucleus receives ascending inputs from the contralateral cochlear nucleus (Friauf and Ostwald 1988; Kuwabara et al. 1991; Thompson and Thompson 1991a,b; Schofield 1995), as well as a substantial local inhibitory input from the ipsilateral MNTB (Kuwabara and Zook 1991, 1992a,b; Banks and Smith 1992; Sommer et al. 1993). It also sends a prominent projection to the ipsilateral inferior colliculus (IC) (Beyerl 1978; Adams 1983; Coleman and Clerici 1987; Moore 1988; Saint Marie and Baker 1990; Gonzalez-Hernandez et al. 1996; Fuentes et al. 1999; Saldaña and Berrebi 2000). Notably, the SPON of the rat does not receive a descending projection from the IC nor does it project to the cochlear nucleus or cochlea (White and Warr 1983; Osen et al. 1984; Faye-Lund 1986; Aschoff and Ostwald 1987; Vetter et al. 1991, 1993; Vetter and Mugnaini 1992; Caicedo and Herbert 1993).

A number of immunohistochemical and retrograde transport studies have revealed populations of GABAimmunoreactive (IR) and glycine-IR neurons in the guinea pig SPON, suggesting that these two neurochemically defined cell groups have different projection targets (Helfert et al. 1989; Thompson et al. 1985; Saint Marie and Baker 1990; Ostapoff et al. 1985, 1990). Recent tract-tracing data in rats, however, demonstrate a homogeneous neuronal population with a purely ipsilateral ascending projection to the IC (Berrebi et al. 1997; Saldaña and Berrebi 2000). Using antibodies directed against GABA or an antiserum that recognizes both isoforms of GAD, other investigators have suggested that the rat SPON contains a substantial proportion of GABAergic neurons (Oertel et al. 1981; Mugnaini and Oertel 1985; Roberts and Ribak 1987; Moore and Moore 1987; Gonzalez-Hernandez et al. 1996). Glycine-IR has been described in the rat SOC (Campistron et al. 1986; Aoki et al. 1988; Pourcho et al. 1992) but has not been systematically examined in the SPON or in other periolivary cell groups.

In order to gain a better understanding of the functional role of SPON, we used immunocytochemical methods to delineate the distribution of GABAergic and glycinergic neurons and axon terminals within the nucleus. We also obtained unbiased stereological estimates of the percentage of SPON neurons that are GAD IR and performed a quantitative morphometric assessment of SPON neuronal morphologies. Some of the data contained herein have been presented in abstract form (Kulesza et al. 1998; Kulesza and Berrebi 1999).

\section{METHODS}

\section{Animals}

Adult female Sprague-Dawley rats, weighing 230-285 $\mathrm{g}$, were deeply anesthetized by an intramuscular injection of a xylazine and ketamine mixture ( $42 \mathrm{mg}$ xylazine and $57 \mathrm{mg}$ ketamine per $100 \mathrm{~g}$ body weight) prior to vascular perfusion. A total of 36 animals were used for this study. The West Virginia University Institutional Animal Care and Use Committee approved all animal protocols used for this project.

\section{Postembedding immunocytochemistry for} glycine and GABA

Twelve animals were perfused through the ascending aorta with a rinse of $\mathrm{Ca}^{2+}$-free Ringer's variant followed by 11 of fixative composed of $2 \%$ paraformaldehyde and $2.5 \%$ glutaraldehyde in $0.1 \mathrm{M}$ sodium phosphate buffer. Animals were placed on ice and remained undisturbed for 30 minutes before their brains were dissected and immersed in fixative overnight. Using a Vibratome, the brains were cut into $100-\mu$ m-thick sections in the coronal plane. The sections were postfixed in $1 \%$ osmium tetroxide, stained with $2 \%$ aqueous uranyl acetate, dehydrated, and flat embedded in Epon (Polybed 812, Polysciences, Warrington, PA). After polymerization, sections containing the SOC 
were cut into a series of $1-\mu \mathrm{m}$ semithin sections, heatdried onto glass slides, and prepared for immunocytochemistry (Spirou and Berrebi 1997). Briefly, Epon was etched from the sections using sodium ethoxide (absolute ethanol saturated with sodium hydroxide). The tissues were then rehydrated, first in ethanols and then in water. Osmium was subsequently removed with $1 \%$ aqueous sodium periodate.

Adjacent pairs of $1-\mu \mathrm{m}$ sections were incubated in $5 \%$ normal donkey serum in $0.5 \mathrm{M}$ Trizma base- $\mathrm{HCl}$ (Tris, pH 7.6) for $1 \mathrm{~h}$ followed by overnight incubation in a primary antiserum as follows: rabbit anti-glycine (Chemicon, Temecula, CA; diluted 1:1200), rabbit anti-GABA (gift from Dr. D. Pow, University of Queensland, Brisbane, Australia: diluted 1:8000; or purchased from HTI Bioproducts, Inc., Ramona, CA, now Strategic BioSolutions: diluted 1:1000). Sections were then incubated in biotinylated secondary antiserum and further processed using the ABC method (Vector, Burlingame, CA). The chromogenic reaction took place in $0.05 \%$ diaminobenzidine (DAB) with $0.01 \%$ hydrogen peroxide in $0.5 \mathrm{M}$ Tris.

The specificity of the Chemicon glycine and Pow GABA antisera was previously established in our laboratory with preadsorption control experiments using an amino acid inhibitor complex according to StormMathisen and Ottersen (1990) (see Fig. 1 of Spirou and Berrebi 1997). The affinity-purified anti-GABA serum from HTI Bioproducts was reported to display approximately $2 \%$ cross-reactivity with glycine. In the present experiments, we tested the effects of antiserum preadsorption on intensity of immunoreactivity using an optical densitometric procedure (see below).

\section{Optical density}

To classify individual cells according to their glycine and/or GABA immunoreactivities, we performed optical densitometry in adjacent semithin ( $1 \mu \mathrm{m}$ thick) sections. A total of six pairs of sections (sections in each pair were within $2-3 \mu \mathrm{m}$ of each other) from the SOC of six animals were used in this analysis. Semithin sections were used because individual neurons could be identified in sequential sections immunostained with either glycine or GABA antiserum. We evaluated every SPON neuron encountered in each section, as well as randomly selected MNTB and MSO cells. The immunostaining intensities of MNTB neurons served as a reference standard for glycine immunopositivity and those of MSO cells as an indication of background immunostaining levels.

Images were captured with a SONY video camera mounted on an Olympus BH-2 microscope (40 times objective, final magnification 980 times). Average pixel grey values were measured from uniform regions of neuronal cytoplasm. Care was taken so that sampling regions within the neuronal cytoplasm did not include the pale staining cell nuclei. The grey value intensity scale was calibrated for each pair of sections so that the darkest staining soma (i.e., a glycine-IR MNTB neuron) was assigned a value of 255 and the lumen of a blood vessel was assigned a value of 0 . Data were entered into JMP (SAS Institute Inc., Cary, NC) and Statview (Abacus Concepts, Inc., Berkeley, CA) data analysis software packages for statistical comparisons and graphical output.

In one pair of sections, the glycine antiserum was preadsorbed with $5 \mathrm{mM}$ GABA and the GABA antiserum was preadsorbed with $10 \mathrm{mM}$ glycine before incubation with the tissue. The optical density data obtained from this pair of sections were statistically indistinguishable from that of the remaining five pairs of sections which were not incubated in preadsorbed antisera $(t=1.819, p>0.07$ for GABA antiserum; and $t=1.056, p>0.29$ for glycine antiserum). Therefore, the effect of preadsorption will not be considered further. We also compared the immunostaining patterns obtained with the GABA antiserum provided by Dr. Pow with the commercially available (HTI Bioproducts) antiserum. Within the range of dilutions we tested, the latter resulted in somewhat weaker staining intensities throughout the brain, but the pattern of immunostaining obtained within nuclei of the SOC were judged to be qualitatively equivalent. Therefore, the data obtained from both GABA antisera were pooled for all analyses.

\section{GAD immunocytochemistry on frozen sections}

A total of 24 animals were perfused through the ascending aorta with a vascular rinse of physiological saline, followed by a fixative composed of $4 \%$ commercial formaldehyde and a zinc salt $(0.5 \%$ zinc dichromate, $\mathrm{pH} 4.0$, or $0.5 \%$ zinc salicylate, $\mathrm{pH} 6.5$ ) in $0.9 \%$ saline (Mugnaini and Dahl 1983; Berrebi and Mugnaini 1991). The animals were placed on ice for 30 minutes before brains were dissected and immersed in cryoprotectant (30\% sucrose in saline) for at least $24 \mathrm{~h}$. Brainstems were sectioned in series order, either coronally or parasagittally, at a thickness of $30 \mu \mathrm{m}$ on a freezing microtome.

Free-floating sections were rinsed in $0.5 \mathrm{M}$ Tris, blocked in $5 \%$ normal donkey serum, and incubated for $48 \mathrm{~h}$ at $4^{\circ} \mathrm{C}$ in primary antiserum with gentle agitation. To optimize the immunostaining, different protocols were used depending on the primary antiserum. GAD-1440 antiserum (Oertel et al. 1981; provided by Judith Harvey-White, NIH, Bethesda, MD, and used at a dilution of $1: 1200$ ) is a sheep polyclonal antiserum that recognizes both GAD isoforms. GAD 6 (Chang and Gottlieb 1988; purchased from Developmental Studies Hybridoma Bank, University of Iowa, and used 
at a dilution of $1: 1000$ ) is a mouse monoclonal antiserum directed against the GAD-65 isoform. Both of these antibodies were revealed using the PAP method (Sternberger 1979), although the best results with the GAD-6 antiserum were obtained with the double PAP method (Ordronneau et al. 1981). K2 antiserum (Kaufman et al. 1991, sold by Chemicon, Temecula, $\mathrm{CA}$, and used at a dilution of 1:3000) is a rabbit polyclonal antiserum that primarily recognizes GAD 67 and was revealed according to the ABC method. The chromogenic reaction for each antiserum took place in $0.05 \% \mathrm{DAB}$ with $0.01 \%$ hydrogen peroxide in $0.5 \mathrm{M}$ Tris. For reference, alternating sections were not immunoreacted but were stained for Nïssl substance using cresyl violet according to standard protocols. All sections were mounted onto glass slides from gelatinalcohol, air-dried, and coverslipped using Accumount.

Specificity assays (preabsorption controls and Western blots) using the GAD 6 and K2 antisera were performed previously by Esclapez et al. (1994). They indicated that the GAD-67-specific $\mathrm{K} 2$ antiserum has a slight cross-reactivity with GAD 65 and that GAD6 antiserum does not cross-react with GAD 67. The specificity of the GAD-1440 antiserum for GAD has been established (Oertel et al. 1981). This antiserum localizes to both isoforms of the enzyme (Kaufman et al. 1991).

\section{Morphometric analysis}

Frozen sections immunoreacted with GAD-1440 or GAD-6 antiserum were sampled at $90-\mu \mathrm{m}$ intervals for further analysis. All labeled neurons containing nuclei were traced using a camera lucida with a 100 times oil immersion objective (final magnification of tissue 1100 times). Care was taken to estimate the cell body contour so that dendrites extending from the soma were not included. The drawings were scanned into a Power Macintosh computer, and NIH Image software (version 1.61, NIH, Bethesda, MD) was used to measure the area, perimeter, and major and minor diameters of each cell body. An index of circularity (Yin et al. 1990) was then calculated for each soma using the equation:

$$
\text { circularity }=4 \pi \text { area } / \text { perimeter }^{2}
$$

which yields an estimate of cell shape that is independent of size. Using this formula, a perfectly circular cell body profile would be assigned a circularity value of 1.0, with increasingly elliptical profiles resulting in decreasing values. Statistical comparisons were performed using the Statview data analysis software package.

\section{Unbiased stereology}

We estimated the number of Nïssl-stained and GADIR neurons in the SPON using methods of unbiased stereology (Gundersen 1988; Gundersen et al. 1988). The Computer Assisted Stereological Toolbox system (C.A.S.T.-Grid, Olympus, Denmark) was used to implement the optical fractionator technique (Gundersen 1986), which incorporates the optical dissector tool (Sterio 1984). We randomly selected a slide caudal to the SPON as a starting point and sampled uniformly spaced sections (every fourth or fifth section) through the nucleus using the optical dissector tool. A counting volume (approximately 33,600 $\mu^{3}{ }^{3}$ ) was defined within the thickness of the tissue section, and only cells that were contained and in focus within the appropriate boundaries of the counting frame were marked. Our final estimates were calculated using the equation:

$$
\begin{aligned}
N= & \text { number of cells counted } \times \text { area fraction } \\
& \times \text { section fraction } \times \text { dissector fraction }
\end{aligned}
$$

Quantitative analysis of puncta in plastic sections

The number of perisomatic puncta was quantified at 100 times under oil immersion (final magnification 1100 times). Measurements of puncta perimeter and long and short axes were made on the computer monitor with the C.A.S.T.-Grid software package using the distance/boundary function. The area of punctate profiles was calculated by modeling them as ellipses using the equation:

$$
\text { Area }_{\text {puncta }}=0.5 \text { major axis } \times 0.5 \text { minor axis } \times \pi
$$

\section{RESULTS}

The subset of SOC sections stained with cresyl violet was used to assist in delineating the boundaries of the SPON and other SOC nuclei. A Nissl-stained coronal section of the rat pons at a middle rostrocaudal level through the SOC is shown for reference in Figure 1. At this level, all three principal nuclei (LSO, MSO, and MNTB) can be identified. Several periolivary cell groups, including the ventral (VNTB) and lateral nuclei of the trapezoid body (LNTB) and the SPON, are also present. The SPON is identified as a prominently sized ovoid-shaped nucleus interposed between the LSO, MSO, and MNTB. In this material, the SPON appears to possess a low density of neurons relative to the MNTB and LSO.

Overview of glycine and GABA immunoreactivities in the SOC

Postembedding immunocytochemistry for glycine and GABA revealed immunolabeled somata, dendrites, 


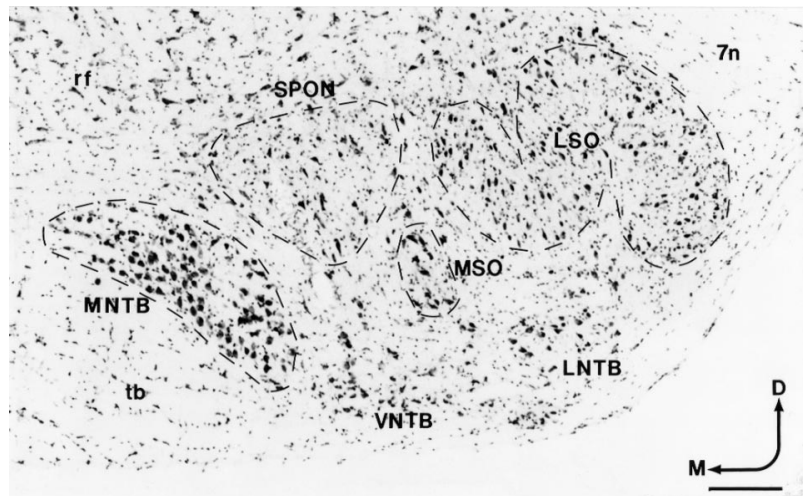

FIG. 1. Organization of the rat superior olivary complex. Cresyl violet-stained coronal section through the SOC at the level of the seventh cranial nerve $(7 n)$ root. The three principal nuclei of the SOC - the lateral superior olive (LSO), medial superior olive (MSO), and the medial nucleus of the trapezoid body (MNTB) — can all be seen in this section, along with several periolivary nuclei. It is evident that the superior paraolivary nucleus (SPON) has a relatively low density of neurons. D-dorsal, LNTB-lateral nucleus of the trapezoid body, M-medial, rf-pontine reticular formation, tb-trapezoid body, VNTB-ventral nucleus of the trapezoid body. Scale bar $=200 \mu \mathrm{m}$.

fibers, and punctate profiles, presumed to represent for the most part axon terminals, throughout the SOC (Fig. 2). Qualitatively, neurons of the MNTB appeared most intensely glycine IR, and the VNTB contained most of the intensely GABA-IR neurons. Glycine- and GABA-IR cell bodies of varying staining intensities were also found scattered in the LSO and LNTB, as well as other nuclei. Cell bodies of the MSO appeared immunonegative after incubation with either antiserum.

The boundary between the SPON and LSO was clearly identified by an immunonegative fiber bundle coursing between these nuclei. The medial border of the SPON was somewhat more difficult to define precisely. In some sections, we noted a thin wedge of tissue located dorsolateral to the MNTB that contained a small number of neurons and a densely immunoreactiveneuropil (Fig. 2). The morphological appearance of these cells suggested that they belong to SPON, but we cannot exclude the possibility that displaced neurons from the MNTB or the reticular formation were occasionally included with the limits of SPON. Nonetheless, inclusive of these few peripherally located cell bodies, the SPON contained only rare somata qualitatively judged to be glycine IR, and such cells were lightly immunostained. Most SPON neurons appeared lightly to moderately GABA IR, while a small percentage were intensely immunolabeled (Figs. 2, 3).

Glycine-IR and GABA-IR puncta were observed throughout the SOC. Glycine-IR punctate profiles were densely distributed in the SPON, the middle and lateral limbs of the LSO, the LNTB, and the VNTB. GABA-IR punctate profiles were also abundant in the

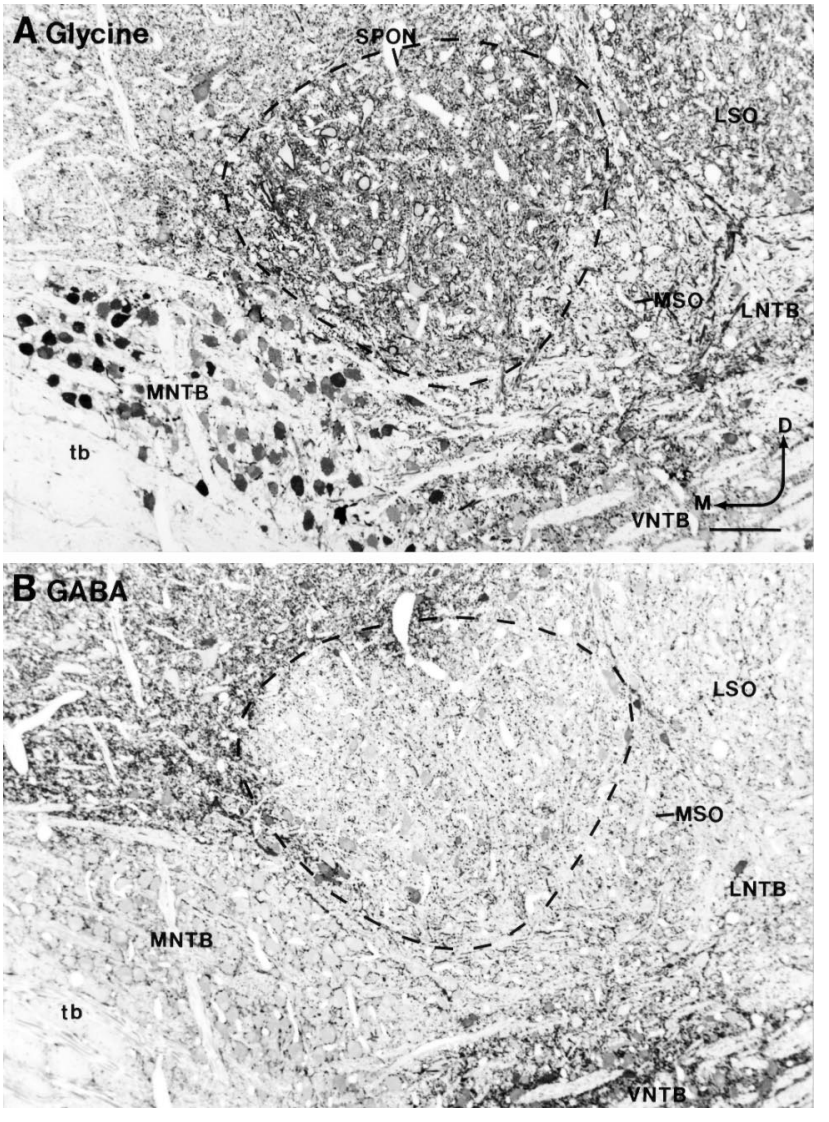

FIG. 2. Overview of glycine IR and GABA IR in the rat SOC. Postembedding immunocytochemistry performed on plastic-embedded semithin sections demonstrates glycine IR and GABA IR within SOC nuclei. A. In glycine material, MNTB neurons are easily recognized by their darkly immunostained somata. The SPON contains only rare glycine-IR cell bodies but the neuropil reveals a high density of glycine-IR fibers and punctate profiles. B. In sections processed to reveal GABA, cell bodies and neuropil in VNTB are the most prominently immunolabeled. SPON contains numerous GABAergic cell bodies, most of which are lightly to moderately immunolabeled. GABA-IR punctate profiles are distributed throughout the neuropil of SPON. Abbreviations as in Fig. 1. Scale bar $=100 \mu \mathrm{m}$.

SPON, although at a lower density than glycine-IR profiles (Fig. 3).

\section{Quantitative analysis of glycine and GABA immunoreactivities}

A quantitative densitometric method was used to classify the glycine and GABA immunoreactivities of SOC neurons (Fig. 4). The IR intensity values representing MNTB neurons were localized to the upper portion of the glycine-IR intensity scale and the lower portion of the GABA-IR intensity scale, while values of MSO neurons were clustered at the lower extreme of both intensity scales. The IR intensity values associated with SPON neurons were widely dispersed across nearlythe entire GABA-IR intensity scale.

The densitometric data are summarized in Table 1 . 


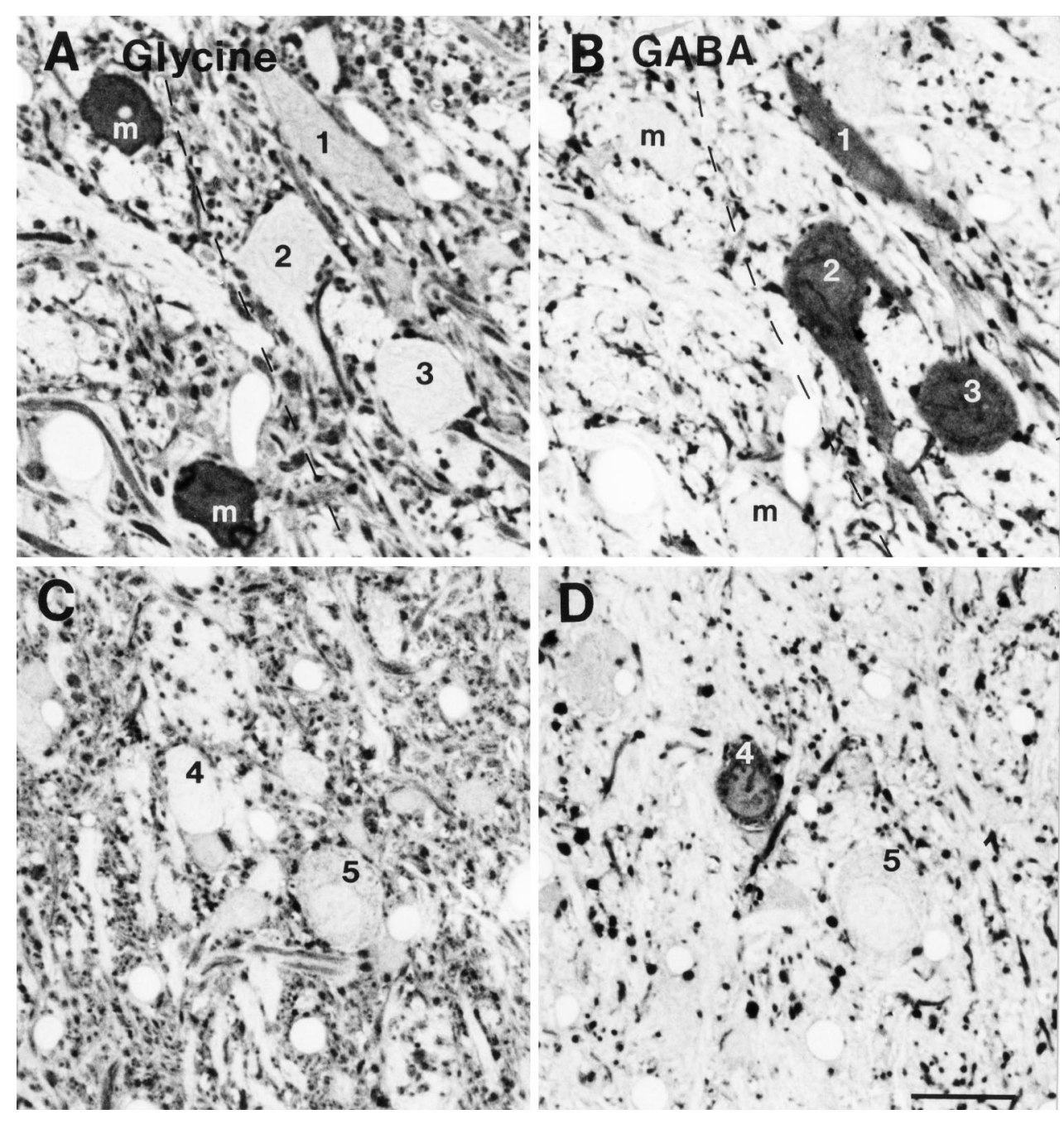

FIG. 3. Glycine IR and GABA IR of the SPON neurons. High-magnification photomicrographs of coronal semithin sections show the range of immunolabeling intensities observed in SPON and MNTB. A, B. Five neurons are shown, and the dashed line denotes the boundary between MNTB and SPON. The two MNTB neurons $(\mathrm{m})$ are distinctly glycine IR and GABA immunonegative. One of the SPON cells (1) displays light glycine IR while all three are intensely GABA IR. C, D. Two additional SPON cells are illustrated. Cell 4 is glycine immunonegative and GABA IR. Cell 5 is lightly glycine IR and GABA immunonegative. Scale bar $=$ $20 \mu \mathrm{m}$.
For clarity of presentation, the immunostaining intensity scales were subdivided into equal thirds roughly corresponding to (1) immunonegative or light IR, (2) moderate IR, and (3) dark IR. Eighty-nine percent of SPON neurons were immunonegative or displayed light glycine-IR intensity, while $11 \%$ displayed moderate glycine-IR intensity. Approximately two-thirds of SPON cells displayed glycine-IR intensities below and GABA-IR intensities above those representing the most intensely immunostained MSO cells. Only 9 SPON cells $(<6 \%)$ displayed glycine-IR intensity values greater than 100 . Nearly half of SPON neurons were immunonegative or displayed light GABA IR, $41 \%$ displayed moderate GABA IR, and $10 \%$ displayed dark GABA IR.

We then performed a logistic regression analysis with group membership (nucleus) as the response and with glycine-IR and GABA-IR intensity values as predictors. Glycine-IR and GABA-IR intensities were both significantly associated with group membership $(p<$ 0.001 level, likelihood ratio chi-squared). All MNTB neurons analyzed were assigned to the correct group membership, while $72 \%$ of MSO neurons and $91 \%$ of SPON neurons were assigned to the proper group. The remaining MSO and SPON neurons, which could not be reliably categorized to either group, all displayed low values for both glycine-IR and GABA-IR intensities. Taken together, we concluded from these data that the vast majority of SPON neurons in the rat express light to moderate GABA immunoreactivity.

GABA-IR and glycine-IR puncta in the SPON. We also performed a quantitative comparison of the innervation densities of SPON neurons by glycinergic and GABAergic puncta. To account for the variations in cross-sectional area of SPON neurons and because of the limited thickness of the sections processed for postembedding immunocytochemistry, we computed the innervation density relative to the perimeter of the SPON neurons. Uniformly throughout the nucleus, SPON somata were apposed to an average of $19.42 \pm$ 0.72 (S.E.M.) glycine-IR puncta per $100 \mu \mathrm{m}$ of somal perimeter. The cross-sectional area of glycine-IR puncta was an average of $2.16 \pm 0.13 \mu \mathrm{m}^{2}$. GABA-IR punctate profiles measured an average of $1.57 \pm 0.91 \mu \mathrm{m}^{2}$ 

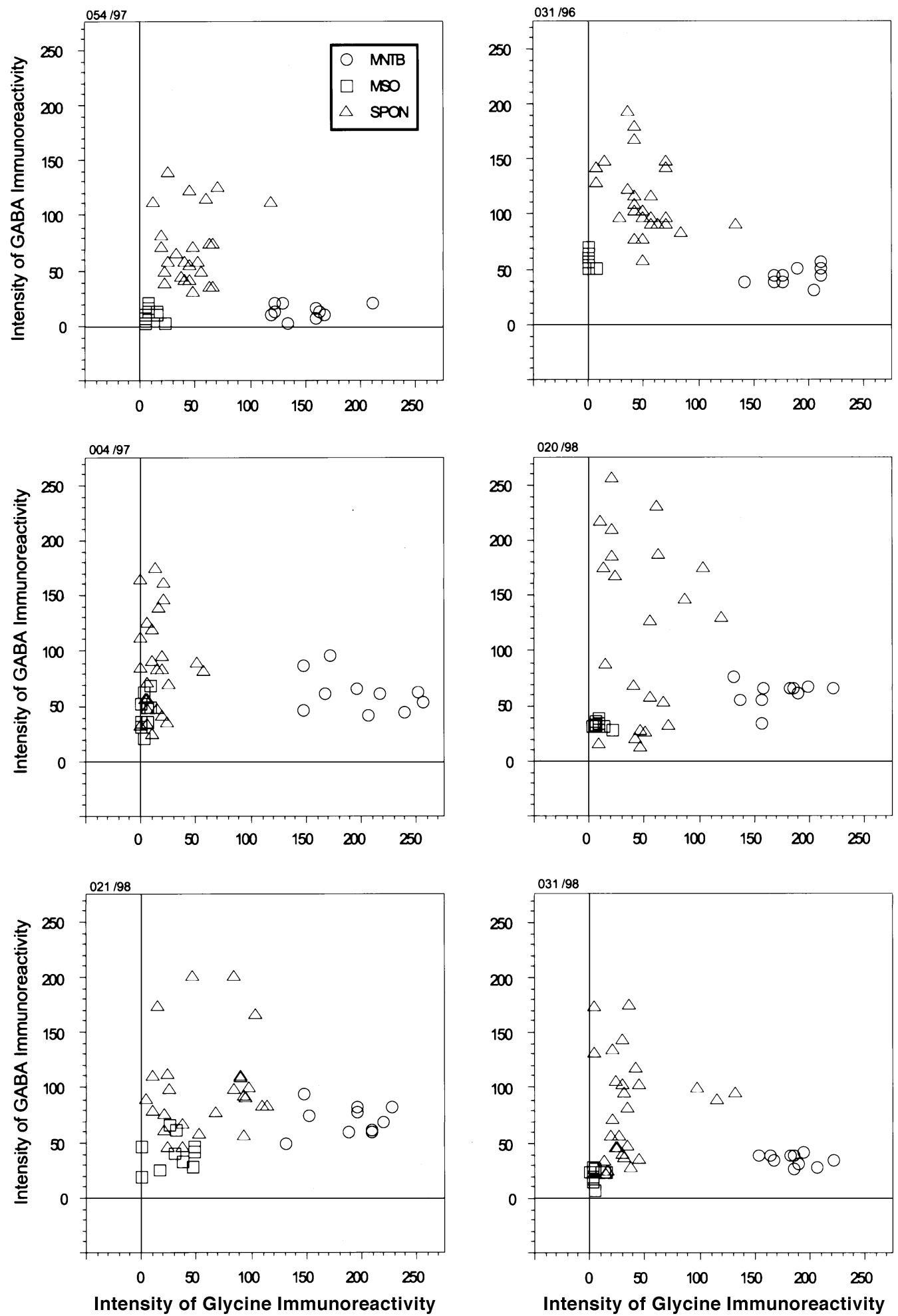

FIG. 4. Assessment of glycine-IR and GABA-IR intensities in somata of the SOC. The same neurons were immunolabeled with antiserum directed against glycine or GABA in adjacent semithin sections from six animals. IR intensity values for MSO cells (squares) cluster at the lower end of both intensity scales. In contrast, the IR intensity values representing MNTB neurons (circles) cluster at the high end of the glycine-IR and the low end of the GABA-IR scales. SPON neurons (triangles) show a wide range of GABA-IR intensities and are the most intensely immunoreactive for GABA among the three nuclei. Glycine-

IR values of SPON neurons are distributed mostly within the lower third of the glycine-IR intensity scale. The number at the top left of each panel indicates the experimental animal identification number. The sections from all animals were incubated with the commercial glycine antiserum (Chemicon) and the GABA antiserum provided by Dr. David Pow, except those from animal 054/97 (top left panel) which were incubated with the commercial GABA antiserum (HTI Bioproducts). In animals 054/97 and 031/96, but not the remaining cases, the antisera were preadsorbed as described in Methods. 


\begin{tabular}{|c|c|c|c|c|c|c|}
\hline \multicolumn{7}{|c|}{ TABLE 1} \\
\hline \multicolumn{7}{|c|}{ Classification of glycine and GABA immunoreactivities in SOC neurons } \\
\hline & \multicolumn{3}{|c|}{ Glycine-IR intensity proportion of cells } & \multicolumn{3}{|c|}{ GABA-IR intensity proportion of cells } \\
\hline Nucleus & $\begin{array}{l}\text { Neg. - Light } \\
(O D=0-85)\end{array}$ & $\begin{array}{c}\text { Moderate } \\
(O D=85-170)\end{array}$ & $\begin{array}{c}\text { Dark } \\
(O D=170-255)\end{array}$ & $\begin{array}{l}\text { Neg. - Light } \\
(O D=0-85)\end{array}$ & $\begin{array}{c}\text { Moderate } \\
(O D=85-170)\end{array}$ & $\begin{array}{c}\text { Dark } \\
(O D=170-255)\end{array}$ \\
\hline $\begin{array}{l}\text { MNTB } \\
(n=60)\end{array}$ & $0 \%$ & $43 \%$ & $57 \%$ & $95 \%$ & $5 \%$ & $0 \%$ \\
\hline $\begin{array}{l}\text { MSO } \\
(n=60)\end{array}$ & $100 \%$ & $0 \%$ & $0 \%$ & $100 \%$ & $0 \%$ & $0 \%$ \\
\hline $\begin{array}{l}\text { SPON } \\
(n=154)\end{array}$ & $89 \%$ & $11 \%$ & $0 \%$ & $49 \%$ & $41 \%$ & $10 \%$ \\
\hline
\end{tabular}

and were found in apposition to somata throughout the SPON. However, somata in the ventro lateral SPON were apposed to an average of $15.04 \pm 0.76$ GABA-IR puncta, whileneurons in the dorsomedial portion of the nucleus were apposed to an average of $23.37 \pm$ 0.96 puncta per $100 \mu \mathrm{m}$ of somal perimeter. This difference in innervation density was statistically significant by ANOVA $(p<0.0001)$.

\section{Overview of GAD IR in the SOC}

GABA is a small labile molecule that can be difficult to localize with immunocytochemistry and may not accumulate to detectable levels in somata of neurons that utilize GABA as neurotransmitter (Ottersen and Storm-Mathisen 1984). Moreover, optimal conditions of tissue fixation and processing to reveal GABA by immunocytochemistry are most conducive to postembedding protocols on thin sections, which are not ideally suited to quantitative morphological and stereological analyses. For these reasons, we chose to employ isoform-specific antisera directed against GAD, the synthesizing enzyme for GABA and a reliable marker of GABAergic neurons (Wu et al. 1973; Oertel et al. 1981; Oertel 1983).

GAD immunocytochemistry revealed cell bodies, dendrites, and punctate profiles throughout the SOC (Figs. 5, 6). The LSO contained a subpopulation of IR neurons situated among immunonegative neurons; it also contained abundant GAD-IR punctate profiles. More LSO somata were immunolabeled by GAD-1440 (cross-reacts with both GAD isoforms) and $\mathrm{K} 2$ antisera (specific for GAD 67; Figs. 5 and 6B) than with GAD6 antiserum (recognizes the 65-kD isoform; Fig. 6A). The MSO and MNTB contained no GAD-IR cells, but neurons in both nuclei were surrounded by numerous GAD-IR puncta. Among the periolivary nuclei, the VNTB contained the most intensely labeled neurons and dense punctate labeling. The LNTB also contained both GAD immunopositive and immunonegative somata as well as GAD-IR punctate profiles. The

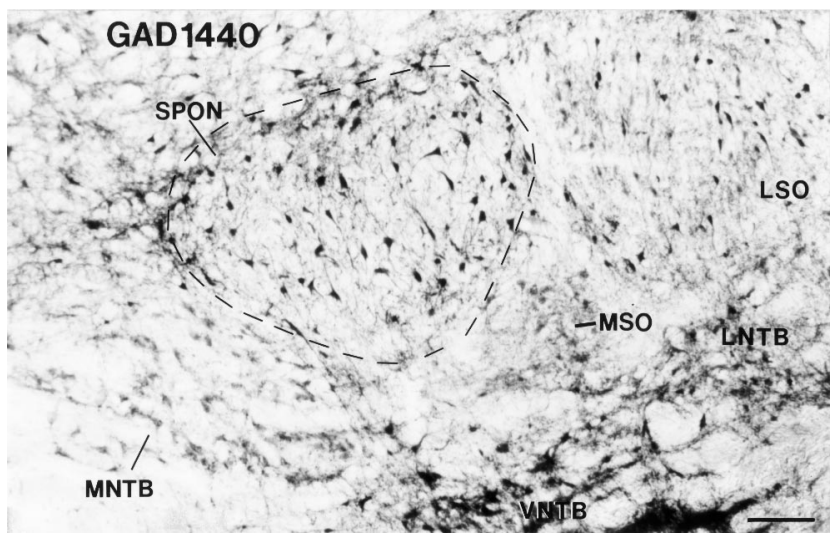

FIG. 5. Immunoreactivity for glutamic acid decarboxylase (GAD) in the SOC. Frozen coronal tissue section processed using the GAD1440 antiserum, which cross-reacts with both isoforms of GAD. The LSO, SPON, VNTB, and LNTB contain GAD-IR neurons. MNTB and MSO neurons are GAD immunonegative but receive GAD-IR innervation which outlines their cell bodies and proximal dendrites. In the coronal plane, most SPON neurons appear bipolar, although round or multipolar forms are also seen occasionally. Scale bar $=100 \mu \mathrm{m}$

SPON contained many labeled neurons and a moderate density of GAD-IR puncta. Overall, the labeling of punctate profiles in the SOC was more intense with the GAD-65-specific GAD-6 antiserum.

\section{GAD-IR somata in the SPON}

Regardless of the antisera used, immunolabeling of SPON neurons appeared as a dark reaction product that filled the cytoplasm and often extended into proximal dendrites. GAD-IR neurons appeared to be evenly distributed throughout SPON, and it was our impression that the vast majority of SPON neurons were GAD IR. Unbiased stereology performed in five animals indicated that the rat SPON contains approximately 2,555 neurons (revealed by cresyl violet counterstaining) and 2,313 GAD-IR neurons (Table 2). Thus, roughly $90 \%$ of SPON neurons express GAD. The 65 and $67-\mathrm{kD}$ isoforms of the enzyme were present in 


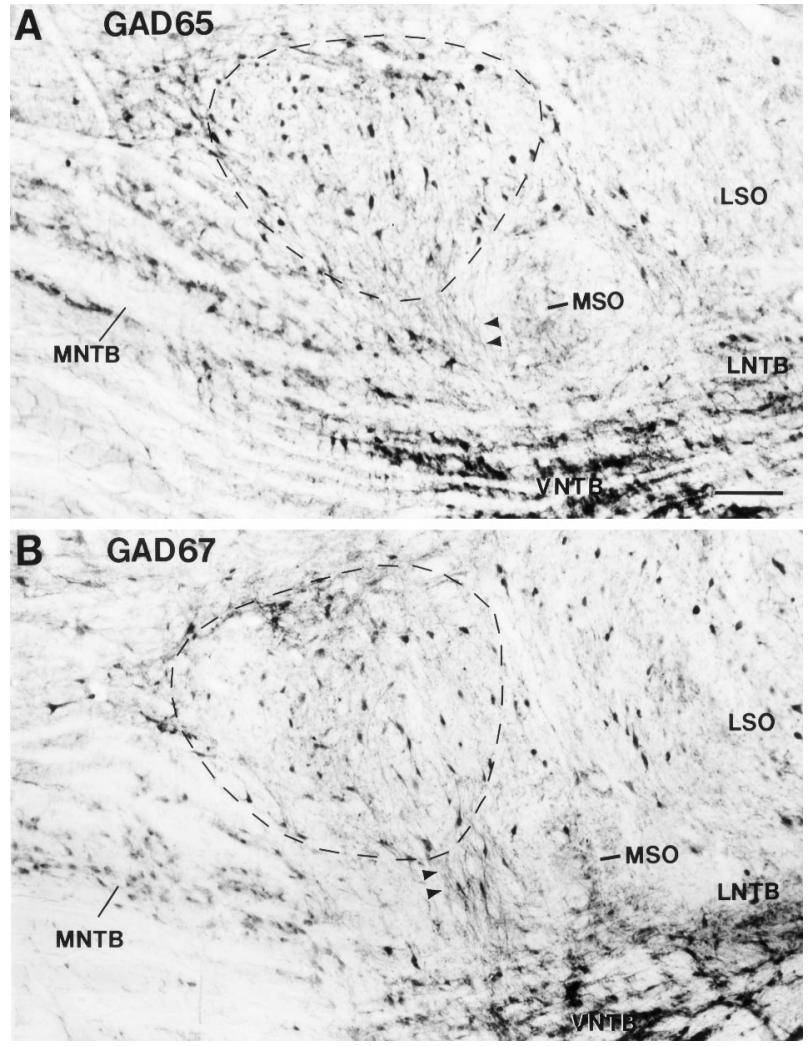

FIG. 6. GAD-65 IR and GAD-67 IR in the SOC. Coronal sections illustrate the distribution of GAD isoforms in the SOC as revealed by antisera specifically directed against either A GAD 65 or B GAD 67. Immunoreactive neurons are present in SPON, VNTB, and LNTB. Fewer LSO neurons were immunolabeled for GAD 65 than for GAD 67. GAD-IR dendrites (arrowheads) appear to extend between the ventral SPON and the VNTB. Scale bar $=100 \mu \mathrm{m}$.

equal numbers of neurons (2,314 and 2,346 neurons, respectively), indicating a great degree of coexpression.

\section{Neuronal morphology}

SPON neurons exhibited some variability in size and shape (Figs. 5, 6). In the coronal plane of section, the majority of GAD-IR SPON neurons were either bipolar or oval with a vertical orientation, while a small fraction appeared to have a multipolar morphology. When viewed in the parasagittal plane, SPON neurons typically displayed a more homogeneous multipolar appearance, with multiple dendrites extending from the soma in various directions (Fig. 7). Parasagittally sectioned profiles of SPON somata (traced separately from their dendrites) were significantly larger and less circular than coronally sectioned profiles (Table 3). These morphometric data, taken together, indicate that typical GAD-IR SPON neurons are large (335.9 $\pm 10.64 \mu \mathrm{m}^{2}$ average cross-sectional area in the parasagittal plane), multipolar cells whose somata and dendritic trees are flattened parasagittally.
TABLE 2

Unbiased estimates of Nïssl-stained and GAD-IR neurons in the rat SPON

\begin{tabular}{lcccc}
\hline & & \multicolumn{2}{c}{ Estimated number of neurons } \\
\cline { 3 - 5 } Animal No. & Isoform & \multicolumn{2}{c}{ GAD } & Nissl \\
\hline $002 / 97 \mathrm{a}^{a}$ & & 2,398 & & \\
$002 / 97 \mathrm{~b}$ & GAD65\&67 & $\underline{2,158}$ & 2,278 & \\
$037 / 98$ & GAD65 & & 2,314 & \\
$024 / 98$ & GAD67 & & 2,346 & \\
$005 / 94$ & - & & & 2,499 \\
$035 / 94$ & - & & & 2,611 \\
\multicolumn{1}{c}{ Overall estimates } & 2,313 & 2,555 & \\
\hline
\end{tabular}

${ }^{a}$ To verify the realibility of the unbiased stereology method in our material, two separate estimates of GAD-IR neurons were obtained from aniaml 002/ 97 using the GAD-1440 antiserum. The number of GAD-IR neurons were then estimated from two other animals using either the GAD-6 or the K2 antiserum. We also estimated the number of Nissl-stained cells in the SPON of two additional animals. Approximately $90 \%$ of SPON neurons are GAD-IR, and each antiserum reveals essentially the same number of cells.

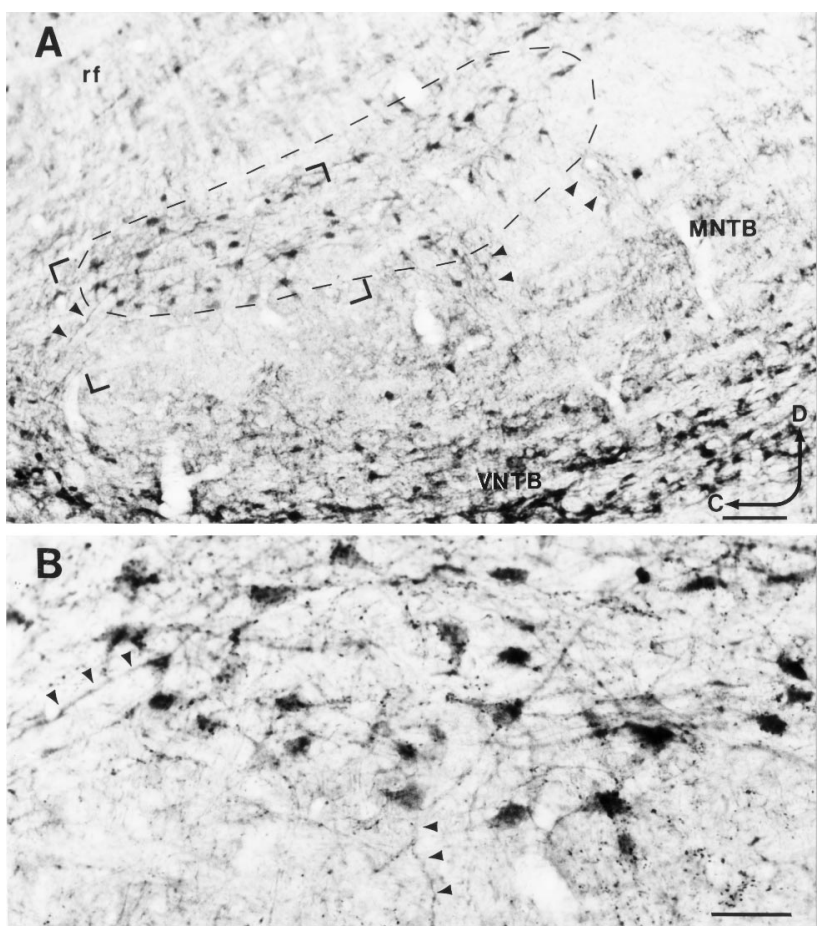

FIG. 7. GAD IR in a parasagittal section through the SOC. A. Frozen parasagittal tissue section processed according to the PAP method using GAD-65 antiserum. At this level through the SOC, portions of the VNTB, MNTB, and SPON (outlined by dashed border) are visible. Bundles of GAD-IR dendrites (arrowheads) are separated by immunonegative fascicles of trapezoid body fibers. B. Higher-magnification photomicrograph of the bracketed region in A. SPON neurons appear distinctly multipolar when sectioned parasagittally. Note also the dense axosomatic and axodendritic GAD-IR innervation of these neurons. In some cases, the ventrally directed GAD-IR dendrites (arrowheads) could be traced to their parent cell bodies in the SPON. C-caudal, D-dorsal, rf-pontine reticular formation. Scale bar $=100$ $\mu \mathrm{m}$ in $\mathbf{A}, 50 \mu \mathrm{m}$ in $\mathbf{B}$. 


\begin{tabular}{|c|c|c|c|c|c|}
\hline \multicolumn{6}{|c|}{ Morphometric analysis of GAD-labeled SPON neurons ${ }^{a}$} \\
\hline $\begin{array}{l}\text { Plane of } \\
\text { section }\end{array}$ & $\begin{array}{c}\text { Mean area } \\
\left(\mu m^{2} \pm S . E .\right)\end{array}$ & $\begin{array}{c}\text { Mean } \\
\text { perimeter } \\
(\mu m \pm S . E .)\end{array}$ & $\begin{array}{c}\text { Mean } \\
\text { maximum } \\
\text { diameter } \\
(\mu m+\text { S.E. })\end{array}$ & $\begin{array}{c}\text { Mean } \\
\text { minimum } \\
\text { diameter } \\
(\mu \mathrm{m} \pm \text { S.E. })\end{array}$ & $\begin{array}{c}\text { Mean } \\
\text { circularity } \\
( \pm \text { S.E. })\end{array}$ \\
\hline Coronal $(n=138)$ & $184.89 \pm 5.74$ & $63.69 \pm 1.22$ & $21.51 \pm 0.43$ & $10.90 \pm 0.24$ & $0.578 \pm 0.01^{b}$ \\
\hline Sagittal $(n=108)$ & $335.90 \pm 10.64^{b}$ & $113.81 \pm 2.42^{b}$ & $29.64 \pm 0.71^{b}$ & $14.61 \pm 0.39^{b}$ & $0.336 \pm 0.01$ \\
\hline
\end{tabular}

In both planes of section, GAD-IR dendrites were seen extending between the SPON and the neuropil of the nearby VNTB (Figs. 6, 7). In coronal sections, these dendrites appeared to form a single narrow bundle. In parasagittal sections it was possible to view a considerable portion of the rostrocaudal extent of the SPON, and GAD-IR dendrites appeared as several small bundles separated by distinct immunonegative fascicles of trapezoid body fibers (Fig. 7). In some cases it was evident that the GAD-IR dendrites belonged to SPON neurons (Fig. 7B).

\section{GAD-IR puncta density in the SPON}

Each of the three antisera used revealed myriad GADIR punctate profiles in SPON, which we interpret as largely representing axon terminals. These puncta were apposed to GAD-IR somata throughout the SPON, forming characteristic perisomatic and peridendritic arrays (Fig. 8). Some of the puncta were connected by delicate fibers, suggesting that they were en passant boutons. GAD-IR puncta were uniform in crosssectional area throughout the nucleus, measuring an average of $1.58 \pm 0.54 \mu \mathrm{m}^{2}$.

\section{DISCUSSION}

\section{Constituent neurons of the SPON}

Previous studies of the rat SOC utilizing antisera to GABA or GAD have revealed a GABAergic population of neurons within the SPON (Mugnaini and Oertel 1985; Li et al. 1995; Gonazalez-Hernandez et al. 1996). Mugnaini and Oertel (1985) did not focus on the SPON per se but, using the same non-isoform-specific GAD-1440 antiserum used in this study, estimated that between $50 \%$ and $90 \%$ of the neurons in the rat SPON were GAD immunoreactive. It has also been reported that aspartate-IR neurons dominate in the rat SPON (Kumoi et al. 1993), but this isolated finding has not been confirmed. In contrast, immunocytochemical studies of guinea pig SPON have described

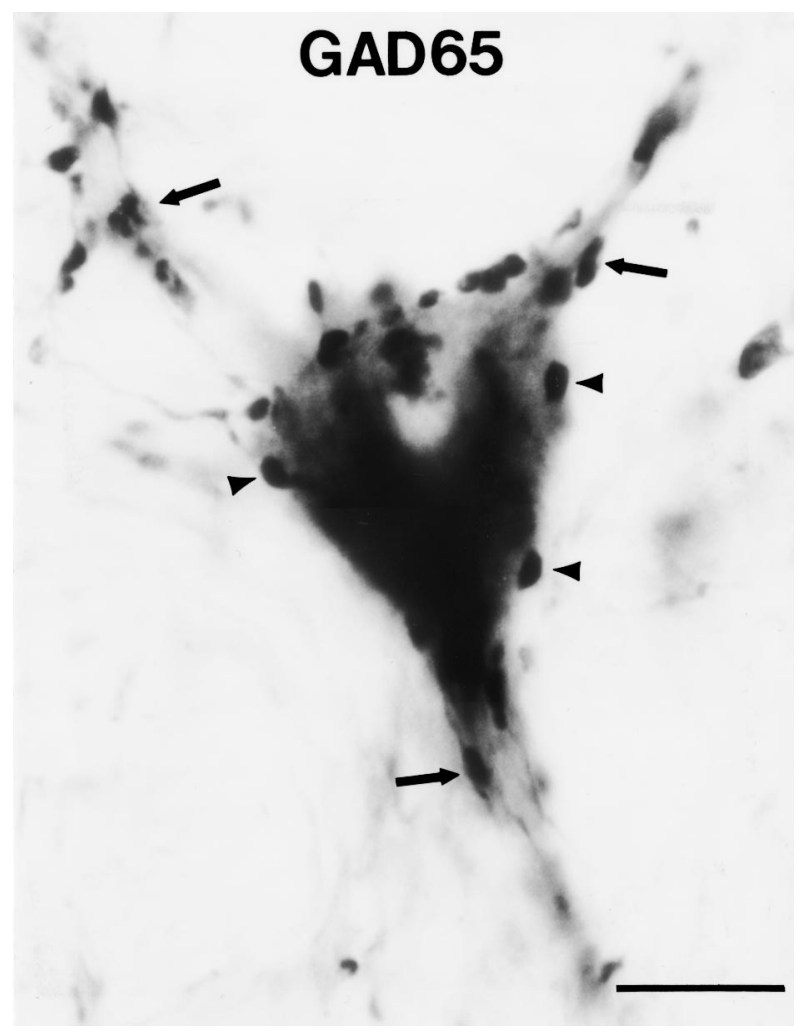

FIG. 8. GAD-IR puncta apposed to a GAD-IR neuron in the SPON. SPON neuron displaying a distinct multipolar morphology and strongly expressing the 65-kD isoform of GAD. Numerous GAD-65IR punctate profiles can be seen apposed to the soma (arrowheads) and dendrites (arrows) of this cell. Scale bar $=10 \mu \mathrm{m}$.

distinct GABAergic and glycinergic neuronal populations (Helfert et al. 1989; Saint Marie and Baker 1990; Ostapoff et al. 1990, 1997). These findings, considered in combination with tract-tracing studies in guinea pig, led Schofield (1991) to suggest that somal morphology and neurochemical phenotype are correlated with efferent projection target of SPON neurons. Our data demonstrate remarkable homogeneity of the SPON of the rat in that the vast majority of rat SPON neurons are immunoreactive for GAD. Moreover, it has been reported recently that virtually all SPON neurons in 
the rat project to the ipsilateral central nucleus of the IC (Saldaña and Berrebi 2000). Taken together, these studies suggest that the rat SPON represents a relatively simply organized nucleus with virtually all of its cells providing a purely GABAergic innervation of the ipsilateral IC. For these reasons, we propose that the rat is an ideal species in which to study the physiology and pharmacology of GABAergic projections.

\section{Colocalization of GAD isoforms in SPON neurons}

The fact that both the 65- and 67-kD isoforms of GAD colocalize in SPON somata is noteworthy. Esclapez and coworkers (1994) reported that in many neurons the two GAD isoforms occupy different intracellular compartments, with GAD 65 highly concentrated in terminals and GAD 67 distributed in both somata and terminals. However, there is molecular evidence that GAD 65 and 67 can form heterodimers (Sheikh and Martin 1996), and biochemical data suggest that GAD 67 is targeted to the perikaryal Golgi membrane via an interaction with GAD 65 (Dirkx et al. 1995). The membrane-bound GAD 65-67 heterodimer is then presumably shipped from the Golgi apparatus to nerve terminals, possibly resulting in the cell body and axon terminal colocalization of GAD isoforms in our study. The production and possible dimerization of GAD 65 in somata may explain our localization of this isoform in SPON perikarya. The precise role of these isoforms in GABAergic neurotransmission and cellular metabolism is not yet understood. Based on counts of GADIR neurons we obtained by unbiased stereology, we report that both isoforms were present in the vast majority of SPON neurons. Even though it is difficult to quantify immunolabeling intensity in our material, the intense labeling found with both the GAD-6 and $\mathrm{K} 2$ antisera suggests that both isoforms are located in somata at relatively high levels. GAD 65 is inactive in the absence of cofactor (pyridoxal 5' phosphate, PLP) and cannot synthesize GABA in cell somata since the cofactor is specifically localized to nerve terminals (Nicholls 1994). Therefore, if GAD 67 is responsible for metabolic processes, such as the GABA shunt which moves glutamate into the Krebs cycle (Baxter 1970), then pools of GABA made by this enzyme are likely to be quickly converted to another metabolite (e.g., succinic semialdehyde) and not be involved in neurotransmission. The inactivity of GAD 65 and the possible metabolic role of GAD 67 might contribute to the common difficulties in revealing GABAergic cell bodies using antisera directed against GABA (e.g., Gonzalez-Hernandez et al. 1996; see also Ottersen and Storm-Mathisen 1994).

\section{Glycinergic and GABAergic inputs to SPON} neurons

Rat SPON neurons express GABA and glycine receptors on their membranes (Friauf et al. 1997, 1998), and we observed abundant glycine IR and GABA IR in the neuropil of the nucleus. Our data and previous reports suggest an extremely dense glycinergic synaptic input to SPON which arises, in large part, from MNTB (Morest 1968; Helfert et al. 1989; Kuwabara and Zook 1991, 1992b; Banks and Smith 1992; Sommer et al. 1993). Our results also coincide with the high concentration of glycine reported in the rat SPON by high-performance liquid chromatography (Godfrey et al. 2000).

The prominent punctate labeling revealed by GABA and GAD immunocytochemistry indicates that SPON also receives GABAergic synaptic input, but the source of this innervation is not known. One candidate is the nearby VNTB, which contains a population of GABAergic neurons (Mugnaini and Oertel 1985; Moore and Moore 1987). In rats, VNTB and SPON display higher GABA concentrations than other SOC nuclei (Godfrey et al. 2000). However, tract-tracing studies in the rat have failed to show such a projection (Warr and Beck 1996), and we consider it unlikely that the VNTB represents a significant source of GABAergic puncta in the SPON.

The lemniscal nuclei are also possible sources of GAD-IR puncta in the SPON. Both the dorsal and ventral nuclei of the lateral lemniscus (DNLL and VNLL) contain GABAergic neurons (Thompson et al. 1985; Moore and Moore 1987; Roberts and Ribak 1987; Gonzalez-Hernandez et al. 1996; Riquelme et al. 1998). Tract-tracing data provide evidence that the DNLL innervates the SOC in rats, although it is uncertain if the SPON receives any of this input (Bajo et al. 1993). The VNLL in cats has been shown to project to the dorsomedial periolivary nucleus (DMPO) (Whitley and Henkel 1984), the presumed homolog of the SPON of rodents, but we are not aware of any reports of a similar projection in the rat.

It is also quite possible, in fact likely, that a proportion of GAD-IR puncta within the SPON arises from branches of SPON axons. Preliminary intracellular labeling experiments from our laboratory indicate that SPON axons collateralize before leaving the nucleus and contact other SPON neurons (Kulesza et al. 2000). Such an arrangement suggests that SPON neurons may provide modulatory feedback to local targets in and around the nucleus. We are particularly interested in this possibility, especially given the recent demonstrations that the SPON of the rat is tonotopically organized (Kelly et al. 1998; Saldaña and Berrebi 2000). 
Furthermore, more refined tracing studies are necessary to adequately resolve these local collaterals and their potential impact on SPON function.

\section{Morphology of SPON neurons}

Our morphometric study complements previous tracttracing work showing that the rat SPON contains a population of multipolar neurons that project to the inferior colliculus and whose somata and dendritic arbors are elongated rostrocaudally and flattened parasagittally (Saldaña and Berrebi 2000). The present data also corroborate the observation that SPON neurons appear different in size and shape depending on the sectioning plane in which they are viewed. Furthermore, their anisotropic organization coincides with the expected geometric arrangement of cells within a tissue displaying a lateral-to-medial tonotopic order of frequency representation, as demonstrated for the SPON (Kelly et al. 1998; Saldaña and Berrebi 2000), since each neuron is expected to receive synaptic inputs localized in mediolaterally restricted territories.

We noted that some ventrally located SPON neurons possessed dendrites that appeared to enter the $\mathrm{VNTB}$, a feature previously demonstrated in retrogradely labeled SPON neurons (Saldaña and Berrebi 2000). Neither the frequency of occurrence nor purpose served by this outgrowth of dendritic processes is clear at this time. However, one can envision that selected SPON neurons may be "sampling" some of the synaptic input received by VNTB cells, including an excitatory descending projection originating in the IC which does not innervate the SPON directly (FayeLund 1986; Rajan 1990; Vetter et al. 1993).

\section{Functional implications}

The SPON receives presumably excitatory projections from octopus and multipolar cells of the ventral cochlear nucleus (Warr 1966; Friauf and Ostwald 1988; Saldaña et al. 1994; Schofield 1995; Finlayson and Adam 1997). Octopus cells display distinct physiological characteristics, such as broad tuning curves and onset responses at characteristic frequency $(\mathrm{CF})$ and pronounced phase locking at low frequency (Godfrey et al. 1975; Rhode et al. 1983; Rhode and Smith 1986). The excitatory multipolar cells, on the other hand, would be expected to provide a frequency tuned and sustained input to SPON (Smith and Rhode 1989). The SPON also receives excitatory input from collaterals of calyciferous bushy cell axons and collaterals of MSO projections (Morest 1968; Smith et al. 1991; Kuwabara and Zook 1999). The integration of excitatory inputs could create a variety of response patterns in the SPON that are difficult to predict. Onset responses could be tuned broadly (from octopus cells) or narrowly (from multipolar and globular cells), and sustained responses (from multipolar cells) may be narrowly tuned and could reveal monaural or binaural (from MSO cells) interactions. These excitatory influences are presumably balanced in SPON by finely tuned glycine-mediated inhibition arising in the MNTB (Banks and Smith 1992; Sommer et al. 1993; Smith et al. 1998) and also by its own GABAergic collateral innervation.

Despite broad tuning in some of its excitatory input, SPON provides a topographic and presumably tonotopic projection to the inferior colliculus (Kelly et al. 1998; Saldaña and Berrebi 2000). GABAergic and glycinergic inhibition originating from the SOC is reported to sharpen tuning curves of IC neurons to certain types of sound (Yang et al. 1992; Koch and Grothe 1998) and influence the temporal firing patterns of IC units (LeBeau et al. 1996), and they are involved in tuning for duration of sound stimuli in the IC (Casseday et al. 1994). GABA is also a powerful mediator of interaural intensity disparity sensitivity in the colliculus (Park and Pollak 1993). Thus, the inhibitory GABAergic projections of the SPON may influence midbrain auditory circuitry in a manner that enables distinction of subtle changes in the frequency and/or temporal characteristics of sounds. There are no published studies of the physiological response properties of rat SPON neurons that shed light on their contribution to the above-mentioned features of collicular physiology. There is evidence from other species that some DMPO and SPON neurons are broadly tuned [cat (Guinan et al. 1972); gerbil (Spitzer and Semple 1995; Dehmel et al. 1999)]. The placement of SPON in a clearer functional context awaits the identification of the source or sources of its abundant GABAergic synaptic input and the physiological response characteristics of its constituent neurons.

\section{ACKNOWLEDGEMENTS}

The authors gratefully acknowledge the excellent technical assistance provided by Mrs. Nancy Irby. We are also indebted to Dr. Gerald Hobbs of the WVU Department of Statistics for expert advice concerning statistical analyses. GAD-1440 antiserum was provided from a source developed at NIH by Drs. Irwin J. Kopin, Wolfgang Oertel, Donald E. Schmechel, and Marcel Tappaz. Current provider of this antiserum is Judith Harvey-White, Bldg. 36, Rm. 5W-21, Bethesda, MD 20892-4164, email: jdhw@box-j.nih.gov. Sincere thanks to Drs. Enrique Saldaña, George Spirou, Donald Godfrey, and Aric Agmon for their valuable presubmission critiques of the manuscript.

This work was supported by research grant DC 02266 to ASB from the National Institute on Deafness and Other Communication Disorders, National Institutes of Health. RJK was supported by a graduate teaching assistantship from the West Virginia University Department of Anatomy. 


\section{REFERENCES}

ADAms JC. Cytology of periolivary cells and the organization of their projections in the cat. J. Comp. Neurol. 215:275-289, 1983.

Aoki E, Semba R, Keino H, Kato K, Kashiwamata S. Glycine-like immunoreactivity in the rat auditory pathway. Brain Res. 442: 63-71, 1988.

Aschoff A, Ostwald J. Different origins of cochlear efferents in some bat species, rats, and guinea pigs. J. Comp. Neurol. 264: 56-72, 1987.

Bajo VM, Merchán MA, Lopez DE, RouilLER EM. Neuronal morphology and efferent projections of the dorsal nucleus of the lateral lemniscus in the rat. J. Comp. Neurol. 334:241-262, 1993.

BANKs MI, SMITH PH. Intracellular recordings from neurobiotinlabeled cells in brain slices of the rat medial nucleus of the trapezoid body. J. Neurosci. 12:2819-2837, 1992.

BAXTER CF. The nature of GABA. In: A Lajtha (ed) Handbook of Neurochemistry. Plenum Press, New York, pp 289-353, 1970.

BAYON A, Possani LD, TAPIA M, TAPIA R. Kinetics of brain glutamate decarboxylase. Interactions with glutamate, pyridoxal 5'-phosphate and glutamate-pyridoxal 5'-phosphate Schiff base. J. Neurochem. 29:519-525, 1977.

Berrebi AS, Mugnaini E. Distribution and targets of the cartwheel cell axon in the dorsal cochlear nucleus of the guinea pig. Anat. Embryol. 183:427-454, 1991.

Berrebi AS, Malmierca MS, Saldaña E. Features of organization of the superior paraolivary nucleus of the rat, guinea pig and chinchilla. Assoc. Res. Otolaryngol. 20:570, 1997.

BEYERL BD. Afferent projections to the central nucleus of the inferior colliculus in the rat. Brain Res. 145:209-223, 1978.

CAICEDO A, HERBERT H. Topography of descending projections from the inferior colliculus to auditory brainstem nuclei in the rat. J. Comp. Neurol. 328:377-392, 1993.

CAMPISTRON G, BuIJS RM, GEFFARD M. Glycine neurons in the brain and spinal cord. Antibody production and immunocytochemical localization. Brain Res. 376:400-405, 1986.

Casseday JH, Ehrlich D, Covey E. Neural tuning for sound duration: Role of inhibitory mechanisms in the inferior colliculus. Science. 264:847-850, 1994

Caspary DM, Backoff PM, Finlayson PG, Palombi PS. Inhibitory inputs modulate discharge rate within frequency receptive fields of anteroventral cochlear nucleus neurons. J. Neurophysiol. 72:2124-2133, 1994.

Chang YC, GotTlieb DI. Characterization of the proteins purified with monoclonal antibodies to glutamic acid decarboxylase. J. Neurosci. 8:2123-2130, 1988.

COLEMAN JR, CleRICI WJ. Sources of projections to subdivisions of the inferior colliculus in the rat. J. Comp. Neurol. 262: 215-226, 1987.

Dehmel S, Doerrscheidt GJ, Reubsamen R. Electrophysiological characterization of neurons in the superior paraolivary nucleus of the gerbil (Meriones unguiculatus). Assoc. Res. Otolaryngol. 22:279, 1999

DENNER LA, WU JY. Two forms of rat brain glutamic acid decarboxylase differ in their dependence on free pyridoxal phosphate. J. Neurochem. 44:957-965, 1985.

Dirkx R, Jr, Thomas A, Li L, Lernmark A, Sherwin RS, De Camilli $\mathrm{P}$, Solimena M. Targeting of the $67-\mathrm{kDa}$ isoform of glutamic acid decarboxylase to intracellular organelles is mediated by its interaction with the NH2- terminal region of the $65-\mathrm{kDa}$ isoform of glutamic acid decarboxylase. J. Biol. Chem. 270:2241-2246, 1995.

Erlander M, Tillakaratne N, Feldblum N, Patel N, Tobin A. Two genes encode distinct glutamate decarboxylases. Neuron. 7:91-100, 1991

ERLANDER MG, TOBIN AJ. The structural and functional heterogeneity of glutamic acid decarboxylase:a review. Neurochem. Res. 16:215-226, 1991
Esclapez M, Tillakaratne NJ, Kaufman DL, Tobin AJ, Houser CR. Comparative localization of two forms of glutamic acid decarboxylase. J. Neurosci. 14:1834-1855, 1994.

FAYE-LUND H. Projection from the inferior colliculus to the superior olivary complex in the albino rat. Anat. Embryol. 175:35-52, 1986.

FinLAYSON PG, ADAM TJ. Excitatory and inhibitory response adaptation in the superior olive complex affects binaural acoustic processing. Hear. Res. 103:1-18, 1997.

FINLAYSON PG, CASPARY DM. Synaptic potentials of chinchilla lateral superior olivary neurons. Hear. Res. 38:221-228, 1989.

FRIAUF E, OSTWALD J. Divergent projections of physiologically characterized rat ventral cochlear nucleus neurons as shown by intraaxonal injection of horseradish peroxidase. Exp. Brain Res. 73:263-284, 1988

Friauf F, Hammerschmidt B, Kirsch J. Development of adult type inhibitory glycine receptors in the central auditory system of rats. J. Comp. Neurol. 385:117-134, 1997.

Friauf E, Fritschy JM, Kuchenbrod T. Differential distribution of GABA-A receptor subunits in the auditory brainstem of adult rats. Assoc. Res. Otolaryngol. 21:457, 1998.

Fuentes V, Berrebi AS, SaldaÑa E. Trajectory, morphology and distribution of axons of the superior paraolivary nucleus that innervate the inferior colliculus in the rat. Assoc. Res. Otolaryngol. 22:885, 1999.

GODFrey DA, KIANG NY, NORRIS BE. Single unit activity in the posteroventral cochlear nucleus of the cat. J. Comp. Neurol. 162: 247-268, 1975.

Godfrey DA, Farms WB, Godfrey TG, Mikesell NL, LiU J. Amino acid concentrations in rat cochlear nucleus and superior olive measured by high performance liquid chromatography. Hear. Res. in press. 2000.

Gonzalez-Hernandez T, Mantolan-Sarmiento B, GonzalezGonzalez B, Perez-Gonzalez H. Sources of GABAergic input to the inferior colliculus of the rat. J. Comp. Neurol. 372: 309-326, 1996.

Guinan JJ, Norris BE, Guinan SS. Single auditory units in the superior olivary complex II: Locations of unit categories and tonotopic organization. Int. J. Neurosci. 4:147-166, 1972.

GUNDERSEN HJ. Stereology of arbitrary particles. A review of unbiased number and size estimators and the presentation of some new ones, in memory of William R. Thompson. J. Microsc. 143: 3-45, 1986.

GUNDERSEN HJ. The nucleator. J. Microsc. 151:3-21, 1988.

Gundersen HJ, Bagger P, Bendtsen TF, Evans SM, Korbo L, Marcussen N, Moller A, Nielsen K, Nyengaard JR, Pakkenberg B. The new stereological tools: disector, fractionator, nucleator and point sampled intercepts and their use in pathological research and diagnosis. Acta. Pathol. Microbiol. Immunol. Scand. 96: 857-881, 1988.

Helfert RH, Bonneau JM, Wenthold RJ, Altschuler RA. GABA and glycine immunoreactivity in the guinea pig superior olivary complex. Brain Res. 6:269-286, 1989.

Helfert RH, Aschoff A. Superior olivary complex and nuclei of the lateral lemniscus. In: G Ehret, R Romand (eds) The Central Auditory System. Oxford University Press, New York, pp 193-258, 1997.

Kaufman DL, Houser CR, Tobin AJ. Two forms of the gammaaminobutyric acid synthetic enzyme glutamate decarboxylase have distinct intraneuronal distributions and cofactor interactions. J. Neurochem. 56:720-723, 1991.

Kelly JB, Liscum A, van Adel B, Ito M. Projections from the superior olive and lateral lemniscus to tonotopic regions of the rat's inferior colliculus. Hear. Res. 116:43-54, 1998.

Klug A, PARK TJ, Pollak GD. Glycine and GABA influence binaural processing in the inferior colliculus of the mustache bat. J. Neurophysiol. 74:1701-1713, 1995. 
Koch U, Grothe B. GABAergic and glycinergic inhibition sharpens tuning for frequency modulations in the inferior colliculus of the big brown bat. J. Neurophysiol. 80:71-82, 1998.

KulEsZa RJ, SAlDAÑa E, BERREBI AS. Distribution of inhibitory neurotransmitters in the superior paraolivary nucleus of the rat. Assoc. Res. Otolaryngol. 21:367, 1998.

KULESZA R, BERREBI AS. Distribution of GAD isoforms in the superior paraolivary nucleus (SPON) of the rat. Assoc. Res. Otolaryngol. 22:278, 1999.

Kulesza R, Holt A, Spirou G, Berrebi AS. Intracellular labeling of axonal collaterals of SPON neurons. Assoc. Res. Otolaryngol. 23:132, 2000.

Kumoi K, SaIto N, Tanaka C. Immunohistochemical localization of gamma-aminobutyric acid- and aspartate-containing neurons in the guinea pig superior olivary complex. Hear. Res. 68: 173-179, 1993.

Kunabara N, DiCAPRIO RA, ZoOK JM. Afferents to the medial nucleus of the trapezoid body and their collateral projections. J. Comp. Neurol. 314:684-706, 1991.

KUWABARA N, ZOOK JM. Classification of the principal cells of the medial nucleus of the trapezoid body. J. Comp. Neurol. 314: 707-720, 1991.

Kuwabara N, Zook JM. Projections to the medial superior olive from the medial and lateral nuclei of the trapezoid body in rodents and bats. J. Comp. Neurol. 324:522-538, 1992a.

KUWABARA N, ZOOK JM. Inputs to the superior paraolivary nucleus. Soc. Neurosci. Abstr. 18:1193, 1992b.

KUWABARA N, ZOOKJM. Local collateral projections from the medial superior olive to the superior paraolivary nucleus in the gerbil. Brain Res. 846:59-71, 1999.

LeBeau FE, Rees A, Malmierca MS. Contribution of GABA- and glycine-mediated inhibition to the monaural temporal response properties of neurons in the inferior colliculus. J. Neurophysiol. 75:902-919, 1996.

LEgaY F, Henry S, TAPPAZ M. Evidence for two distinct forms of native glutamic acid decarboxylase in rat brain soluble extract: an immunoblotting study. J. Neurochem. 48:1022-1026, 1987.

Li L, Wu SH, Zhang DX, KeLly JB. GABAergic projections to the central nucleus of the inferior colliculus of the rat: a combination of fluorogold retrograde tracing with immunocytochemistry. Soc. Neurosci. Abstr. 25:166.13, 1995.

MaRTIN DL, MARTIN SB, WU SJ, EsPina N. Regulatory properties of brain glutamate decarboxylase GAD: the apoenzyme of GAD is present principally as the smaller of two molecular forms of GAD in brain. J. Neurosci. 11:2725-2731, 1991.

MARTIN DL, Rimvall K. Regulation of gamma-aminobutyric acid synthesis in the brain. J. Neurochem. 60:395-407, 1993.

MOORE DR. Auditory brainstem of the ferret: sources of projections to the inferior colliculus. J. Comp. Neurol. 269:342-354, 1988.

MOORE JK, MOORE RY. Glutamic acid decarboxylase-like immunoreactivity in brainstem auditory nuclei of the rat. J. Comp. Neurol. 260:157-174, 1987.

MOREST DK. The growth of synaptic endings in the mammalian brain: a study of the calyces of the trapezoid body. Z. Anat. Entwicklungsgesch. 127:201-220, 1968.

Mugnaini E, DAHL AL. Zinc-aldehyde fixation for light-microscopic immunocytochemistry of nervous tissues. J. Histochem. Cytochem. 31:1435-1438, 1983.

Mugnaini E, Oertel WH. An atlas of the distribution of GABAergic neurons and terminals in the rat CNS as revealed by GAD immunohistochemistry. In: A Björklund, T Hökfelt (eds) Handbook of Chemical Neuroanatomy. Vol. 4: GABA and Neuropeptides in the CNS, Part I. Elsevier Science Publishers, Amsterdam, pp 436-608, 1985.

NicHOLLs D. Blackwell Science Ltd., Oxford Proteins, Transmitters and Synapses. 1994.
Oertel W, SChMechel D, Mugnaini E, TAPPAZ M, Kopin I. Immunocytochemical localization of glutamate decarboxylase in rat cerebellum with a new antiserum. Neuroscience. 6:2715-2735, 1981.

OERTEL W. Synaptic responses and electrical properties of cells in brain slices of the mouse anteroventral cochlear nucleus. J. Neurosci. 3:2043-2053, 1983.

ORDRONNEAU P, LindSTROM PB, PETRUSZ P. Four unlabeled antibody bridge techniques: a comparison. J. Histochem. Cytochem. 29:1397-1404, 1981.

Osen KK, Mugnaini E, Dahl A-L, Christiansen AH. Histochemical localization of acetylcholinesterase in the cochlear and superior olivary nuclei. A reappraisal with emphasis on the cochlear granule cell system. Arch. Ital. Biol. 122:169-212, 1984.

Ostapoff EM, Morest DK, Potasher SJ. Retrograde transport of ${ }^{3} \mathrm{H}-\mathrm{GABA}$ from the cochlear nucleus to the superior olive in guinea pig. Soc. Neurosci. Abstr. 11:1051, 1985.

Ostapoff EM, Morest DK, Potashner SJ. Uptake and retrograde transport of $\left[{ }^{3} \mathrm{H}\right] \mathrm{GABA}$ from the cochlear nucleus to the superior olive in the guinea pig. J. Chem. Neuroanat. 3:285-295, 1990.

Ostapoff EM, Benson CG, Saint Marie RL. GABA- and glycineimmunoreactive projections from the superior olivary complex to the cochlear nucleus in guinea pig. J. Comp. Neurol. 381: 500-512, 1997.

OtTERSEN OP, StORM-Mathisen J. Glutamate- and GABA-containing neurons in the mouse and rat brain, as demonstrated with a new immunocytochemical technique. J. Comp. Neurol. 229:374-392, 1984.

PARK TJ, POLLAK GD. GABA shapes sensitivity to interaural intensity disparities in the mustache bat's inferior colliculus: implications for encoding sound location. J. Neurosci. 13:2050-2067, 1993.

Pourcho RG, Goebel DJ, Jojich L, Hazlett JC. Immunocytochemical evidence for the involvement of glycine in sensory centers of the rat brain. Neuroscience. 46:643-656, 1992.

RAJAN R. Electrical stimulation of the inferior colliculus at low rates protects the cochlea from auditory desensitization. Brain Res. 506:192-204, 1990.

Rhode WS, Oertel D, Smith PH. Physiological response properties of cells labeled intracellularly with horseradish peroxidase in cat ventral cochlear nucleus. J. Comp. Neurol. 213:448-463, 1983.

RHODE WS, SMITH PH. Encoding timing and intensity in the ventral cochlear nucleus of the cat. J. Neurophysiol. 56:261-286, 1986.

Riguelme R, Merchan MA, Ottersen OP. GABA and glycine in the ventral nucleus of the lateral lemniscus: An inmunocytochemical and in situ hybridization study in rat. Assoc. Res. Otolaryngol. 21:370, 1998.

Roberts E, Frankel S. Gamma-butyric acid in brain: Its formation from glutamic acid. J. Biol. Chem. 187:55-63, 1950.

RoBerts RC, RiBAK CE. GABAergic neurons and axon terminals in the brainstem auditory nuclei of the gerbil. J. Comp. Neurol. 258:267-280, 1987.

SAINT MARIE RL, BAKer RA. Neurotransmitter-specific uptake and retrograde transport of $\left[{ }^{3} \mathrm{H}\right]$ glycine from the inferior colliculus by ipsilateral projections of the superior olivary complex and nuclei of the lateral lemniscus. Brain Res. 524:244-253, 1990.

SAldaña E, LOUgh DR, BerRebi AS. Superior Paraolivary Nucleus SPON: Connectivity revealed by transport of dextran amine. Soc. Neurosci. Abstr. 20:975, 1994.

SALDAÑA E, BERREBI AS. Anisotropic organization of the rat superior paraolivary nucleus. Anat. Embryol. in press. 202:265-279, 2000.

SCHOFIELD BR. Superior paraolivary nucleus in the pigmented guinea pig:separate classes of neurons project to the inferior colliculus and the cochlear nucleus. J. Comp. Neurol. 312:68-76, 1991.

SCHOFIELD BR. Projections from the cochlear nucleus to the superior paraolivary nucleus in guinea pigs. J. Comp. Neurol. 360: 135-149, 1995. 
SCHWARTZ IR. The superior olivary complex and the lateral lemniscal nuclei. In: DB Webster, AN Popper, RR Fay (eds) Mammalian Auditory Pathways: Neuroanatomy. Springer-Verlag, New York, pp 117-167, 1992.

SHEIKH SN, MarTin DL. Heteromers of glutamate decarboxylase isoforms occur in rat cerebellum. J. Neurochem. 66:2082-2090, 1996.

SMITH PH, RHOde WS. Structural and functional properties distinguish two types of multipolar cells in the ventral cochlear nucleus. J. Comp. Neurol. 4:595-616, 1989.

SMITH PH, JORIS PX, CARNEY LH, YIN TC. Projections of physiologically characterized globular bushy cell axons from the cochlear nucleus of the cat. J. Comp. Neurol. 304:387-407, 1991.

SMITH PH, JoRIS PX, YIN TC. Anatomy and physiology of principal cells of the medial nucleus of the trapezoid body MNTB of the cat. J. Neurophysiol. 79:3127-3142, 1998.

SOMmer I, Lingenhohl K, Friauf E. Principal cells of the rat medial nucleus of the trapezoid body: an intracellular in vivo study of their physiology and morphology. Exp. Brain Res. 95:223-239, 1993.

SPINK DC, WU SJ, Martin DL. Multiple forms of glutamate decarboxylase in porcine brain. J. Neurochem. 40:1113-1119, 1983.

SpIRou GA, Berrebi AS. Glycine immunoreactivity in the lateral nucleus of the trapezoid body of the cat. J. Comp. Neurol. 383:473-488, 1997.

Spitzer MW, Semple MN. Neurons sensitive to interaural phase disparity in gerbil superior olive: diverse monaural and temporal response properties. J. Neurophysiol. 73:1668-1690, 1995.

STERIO DC. The unbiased estimation of number and sizes of arbitrary particles using the disector. J. Microsc. 134:127-136, 1984.

STERnBERGER LA. Immunocytochemistry. Wiley, New York 1979.

StORM-Mathisen J, OtTersen OP. Antibodies and fixatives for the immunocytochemical localization of glycine. In: OP Ottersen, J Storm-Mathisen (eds) Glycine Neurotransmission. John Wiley and Sons, New York pp 281-302, 1990.
THOMPSOn GC, Cortez AM, LAM DM. Localization of GABA immunoreactivity in the auditory brainstem of guinea pigs. Brain Res. 339:119-122, 1985

Thompson AM, ThOMPson GC. Projections from the posteroventral cochlear nucleus to the superior olivary complex in guinea pig: light and EM observations with the PHA-L method. J. Comp. Neurol. 311:495-508, 1991a.

ThOMPSON AM, ThOMPSON GC. Posteroventral cochlear nucleus projections to olivocochlear neurons. J. Comp. Neurol. 303: 267-285, 1991b.

Vetter DE, Adams JC, Mugnaini E. Chemically distinct rat olivocochlear neurons. Synapse. 7:21-43, 1991.

Vetter DE, Mugnaini E. Distribution and dendritic features of three groups of rat olivocochlear neurons. A study with two retrograde cholera toxin tracers. Anat. Embryol. 185:1-16, 1992.

VetTer DE, Saldaña E, Mugnaini E. Input from the inferior colliculus to medial olivocochlear neurons in the rat: a double label study with PHA-L and cholera toxin. Hear. Res. 70:173-186, 1993.

WARR WB. Fiber degeneration following lesions in the anterior ventral cochlear nucleus of the cat. Exp. Neurol. 14:453-474, 1966.

WARR WB, BECK JE. Multiple projections from the ventral nucleus of the trapezoid body in the rat. Hear. Res. 93:83-101, 1996.

WHITE JS, WARR WB. The dual origins of the olivocochlear bundle in the albino rat. J. Comp. Neurol. 219:203-214, 1983.

Whitley JM, Henkel CK. Topographical organization of the inferior collicular projection and other connections of the ventral nucleus of the lateral lemniscus in the cat. J. Comp. Neurol. 229: 257-270, 1984.

Wu JY, MATSudA T, Roberts E. Purification and characterization of glutamate decarboxylase from mouse brain. J. Biol. Chem. 248:3029-3034, 1973.

YIN TCT, CHAN JCK. Interaural time sensitivity in the medial superior olive of the cat. J. Neurophysiol. 65:465-488, 1990.

Yang L, Pollak GD, Resler C. GABAergic circuits sharpen tuning curves and modify response properties in the mustache bat inferior colliculus. J. Neurophysiol. 68:1760-1774, 1992. 